Research Article

\title{
Temperature Correction for FWD Deflection in Cement Pavement Void Detection
}

\author{
Bei Zhang $\left(\mathbb{D}\right.$, Xiaoliang Wang, Yanhui Zhong $\left(\mathbb{D}\right.$, Xiaolong Li $\mathbb{D}^{D}$, Meimei Hao $(\mathbb{D}$, \\ Yuanhao Ding, Jianyang Liu, and Xu Zhang
}

College of Water Conservancy and Engineering, Zhengzhou University, Zhengzhou 450001, China

Correspondence should be addressed to Yanhui Zhong; zhong_yanhui@163.com and Xiaolong Li; wennuandeshang@ hotmail.com

Received 9 December 2020; Revised 20 January 2021; Accepted 27 January 2021; Published 10 February 2021

Academic Editor: Jiaolong Ren

Copyright (c) 2021 Bei Zhang et al. This is an open access article distributed under the Creative Commons Attribution License, which permits unrestricted use, distribution, and reproduction in any medium, provided the original work is properly cited.

\begin{abstract}
The use of the falling weight deflectometer (FWD) for detecting pavement voids is based on the principle that, under the same impact load, the deflection of pavements with voids increases significantly. Under the effect of temperature, the cement pavement becomes warped, which affects the deflection detection accuracy. In order to improve the accuracy of FWD detection of cement pavement voids, a three-dimensional numerical model of cement pavement on a multilayered elastic foundation under the coupled action of temperature and load is established in this paper. In addition, under different pavement void, climatic, and load conditions, the influence of temperature difference between top and bottom of the plate on the deflection of the center point of plate angle load is studied. Considering the temperature difference between top and bottom, the temperature correction coefficient is established and experimentally verified the accuracy of the temperature correction coefficient. The results showed that, within the ranges of positive and negative temperature differences, the fitting degree of the temperature correction coefficient for the cement pavement exceeded 0.99 , which was consistent with the variation trend of the temperature correction coefficient obtained through field tests. The error was lower than 7\%, which verified the applicability of the temperature correction coefficient for the dynamic deflection of cement pavements based on FWD. The accuracy of the FWD method in detecting cement pavement voids was improved, and this study demonstrated theoretical reference value and practical engineering significance.
\end{abstract}

\section{Introduction}

Cement concrete pavement structures have advantages of extended service life, strong load diffusion capacity, easy constructability, accessibility of constituent materials, and low cost, and they are widely used for all types of highways [1]. However, during the service life of cement pavement, the pavement is prone to experience cracks, disconnections, voids, and other problems, owing to the combined action of the driving load and external environment. These problems have a significant impact on driving comfort and human safety [2]; the most significant impact on traffic is attributed to the voids in the cement concrete pavement $[3,4]$. After concrete pavement voids are formed, the accurate and rapid detection of void damage in the concrete pavement is the focus of several studies.
Scholars have investigated the detection of voids in cement pavements, among which the most widely used technique is the void determination method based on the deflection. The void determination method is mainly divided into two types: falling weight deflectometer detection and Benkelman beam test $[5,6]$. The FWD detection is used more widely because of its established technique and easy implementation. FWD detection is based on the principle that, under the same impact load, the deflection of the void area increases significantly [7-12]. Because of the influence of climatic factors, such as solar radiation and ambient temperature, cement pavement panels experience temperature warping at different degrees [13-15], which affect the accuracy of actual pavement detection results. Wen et al. systematically analyzed the impact of pavement voids under the coupled action of environment and load, described the 
formation process of voids, and highlighted the significant causes of cement concrete bottom voids [16]. Zeng et al. used ANSYS and the FWD method to measure the deflection data of the panel center and panel angle of cement pavement and developed a method of estimating the scope of the panel angle void of cement pavements [17]. Chen et al. established a three-dimensional model of cement concrete pavement voids, verified the accuracy of the model by comparing its results with theoretical solutions and measured values, and proposed an analytical method for identifying cement concrete pavement voids [18]. Toth et al. evaluated the fouryear meteorological data and deflection measurements of a section in Hungary, analyzed the variation of deflection parameters at different periods, and formulated correction factors based on the assessment results [19]. Through field observations, theoretical analysis, and relevant calculations, Jing et al. developed a method to determine the pavement temperature gradient using local meteorological data of several years [20]. Duan et al. performed simulation calculations on cement concrete pavement, analyzed the variation trend of the temperature stress of the plate angle under the conditions of complete contact with the pavement and plate angle void, and determined the main factors that influenced the temperature stress of the plate angle [21]. Based on a systematic analysis of the warping deformation of the sidewalk panel under a positive temperature gradient, Zhao et al. determined the modifiable temperature gradient of the internal deflection of a sidewalk panel. They established the correction method and the corresponding regression expression of the FWD test panel internal deflection [22]. Sheng et al. proposed improvement measures for the deflection test on old cement concrete pavements, evaluated the deflection of the solid engineering plate angle, plate center, and joint edge, and determined the reasonable temperature of the deflection test [23]. Dou et al. adopted the stress intensity factor as the evaluation criterion to perform three-dimensional finite element simulation of early pavement fracture expansion based on the theory of linear-elastic fracture mechanics. They analyzed the effects of fracture depth, overload, and temperature on fracture expansion [24]. Currently, studies on cement pavement temperature fields and FWD on pavement void detection have been conducted, but research on FWD pavement void detection under the coupled action of temperature and load have not been conducted in detail.

Therefore, through the establishment of a threedimensional numerical model for cement pavements under temperature and load coupling and the pavement plate deflection under the temperature and load coupling under different climatic and void conditions, the temperature difference between the top and bottom was analyzed. The correlation of deflection temperature correction coefficient was established, and the temperature correction coefficient was developed by considering the temperature difference between the top and bottom. Furthermore, the accuracy of the temperature correction coefficient was verified experimentally. The research results are useful for improving the accuracy of the FWD method for detecting cement pavement voids in different climates.

\section{Three-Dimensional Numerical Model of Cement Pavement under Coupling of Temperature and Load}

2.1. Basic Assumptions. In this study, a three-dimensional numerical model of cement concrete pavement was established for the analysis of the influence of the temperature field on the deformation of a cement concrete pavement slab. The following basic assumptions were made:

(1) The material layers are homogeneous and isotropic linear elastomers, characterized by the elastic modulus and Poisson's ratio

(2) Except for the panel, each layer in the horizontal direction is an infinite elastomer, while the lowest layer is a homogeneous semi-infinite body

(3) The displacements and stresses in all directions of the contact surfaces between layers are entirely continuous, and the transfer of the force and displacement only occurs when the contact surfaces are in the void region

2.2. Establishment of Void Model. In this study, two types of pavement bottom void were used: the plate angle void and the plate edge void. The plate angle void area was set as a cylindrical sheet with the corner vertex as the center of the circle, whereas the plate edge void was set as a cuboid sheet with a length, width, and height and the panel width adopted as the long side. The voids were combined into $16(4 \times 4)$ plate angle void conditions and $16(4 \times 4)$ plate edge void conditions. Table 1 lists the size setting of the void condition, and Figure 1 shows the plate angle and plate edge of the void model.

2.3. Material Parameters. The model size and material parameter setting of each structure layer were determined (Table 2) to simulate the actual cement concrete pavement structure better.

\subsection{Load and Boundary Conditions}

2.4.1. Temperature and Load Applications. The temperature stress was applied to input the corresponding value directly into the plate top and bottom of the cement concrete pavement during the initial step of the load setting. Based on the data for the measured temperature and temperature difference between the top and bottom of the plate in each season listed in Table $3,25^{\circ} \mathrm{C}$ and $-25^{\circ} \mathrm{C}$ were selected as the upper and lower limits of the temperature difference between the top and bottom, and the temperature gradient was set as $5^{\circ} \mathrm{C}$.

The temperatures of the cement concrete pavement slab for a monitoring period of one year in four seasons were analyzed. There was a significant linear relationship between the top temperature of the plate and the bottom temperature difference of the plate $[25,26]$. The correlation equations between the top temperature of the plate and the bottom temperature difference of the plate for the cement concrete pavement in each season are listed in Table 4. 
TABLE 1: Size setting of void conditions.

\begin{tabular}{lccc}
\hline & Plate angle void & & Plate edge void \\
Radius $(\mathrm{m})$ & Height $(\mathrm{cm})$ & Width $(\mathrm{m})$ & Height $(\mathrm{cm})$ \\
\hline 0.25 & 0.50 & 0.25 & 0.50 \\
0.50 & 1.00 & 0.50 & 1.00 \\
0.75 & 1.50 & 0.75 & 1.50 \\
1.00 & 2.00 & 1.00 & 2.00 \\
\hline
\end{tabular}

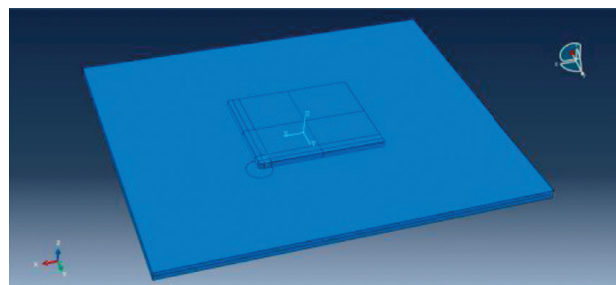

(a)

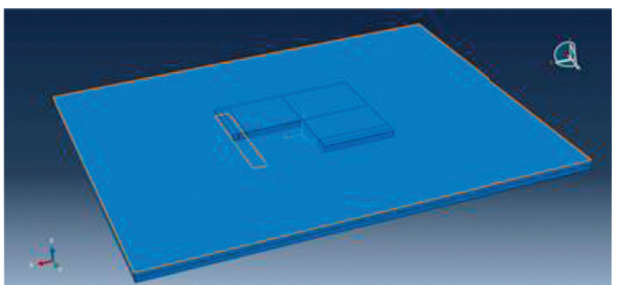

(b)

Figure 1: Schematic of plate angle and edge voids of the cement pavement. (a) Plate angle void of cement pavement. (b) Plate edge void of cement pavement.

TABLE 2: Material parameters of each structure layer of cement concrete pavement.

\begin{tabular}{lccccc}
\hline $\begin{array}{l}\text { Structure } \\
\text { layer }\end{array}$ & $\begin{array}{c}\text { Plane dimension } \\
\left(\mathrm{m}^{2}\right)\end{array}$ & $\begin{array}{c}\text { Thickness } \\
(\mathrm{cm})\end{array}$ & $\begin{array}{c}\text { Modulus of elasticity } \\
(\mathrm{MPa})\end{array}$ & $\begin{array}{c}\text { Poisson's } \\
\text { ratio }\end{array}$ & $\begin{array}{c}\text { Thermal conductivity } \\
\left(\omega \cdot \mathrm{m}^{-1} \cdot{ }^{\circ} \mathrm{C}^{-1}\right)\end{array}$ \\
\hline Surface & $5 \times 4$ & 24 & 30000 & 0.15 & 1.34 \\
Base & $15 \times 12$ & 16 & 500 & 0.3 & - \\
Subbase & $15 \times 12$ & 18 & 400 & 0.3 & - \\
\hline
\end{tabular}

TABle 3: Measured temperature and temperature difference between top and bottom of the plate in each season.

\begin{tabular}{lcccccccc}
\hline \multirow{2}{*}{ Season } & \multicolumn{2}{c}{ Maximum } & \multicolumn{2}{c}{ Minimum } & \multicolumn{2}{c}{ Average } & \\
& temperature $\left({ }^{\circ} \mathrm{C}\right)$ & \multicolumn{2}{c}{ temperature $\left({ }^{\circ} \mathrm{C}\right)$} & \multicolumn{2}{c}{ temperature $\left({ }^{\circ} \mathrm{C}\right)$} & Temperature range $\left({ }^{\circ} \mathrm{C}\right)$ & Mean temperature difference $\left({ }^{\circ} \mathrm{C}\right)$ \\
& Top & Bottom & Top & Bottom & Top & Bottom & & \\
\hline Spring & 51.60 & 37.30 & 1.00 & 5.20 & 22.46 & 21.34 & -6.80 to 16.00 & 4.46 \\
Summer & 57.20 & 49.70 & 18.90 & 23.80 & 33.36 & 32.44 & -9.90 to 19.50 & 0.81 \\
Autumn & 44.10 & 35.30 & 2.76 & 8.30 & 18.79 & 18.13 & -2.00 to 10.00 & 1.87 \\
Winter & 18.80 & 5.00 & -5.50 & 1.20 & 2.70 & 3.38 & -7.10 to 15.00 & -0.68 \\
\hline
\end{tabular}

TABLE 4: Correlation equations expressing the relationship between the top temperature of cement concrete pavement plate and bottom temperature difference of plate.

\begin{tabular}{lcc}
\hline Season & Plate top temperature $T_{\text {top }}$-plate bottom temperature difference $\nabla T$ relationship \\
\hline Spring & $\nabla T=0.5039 \cdot T_{\text {top }}-6.8963$ \\
Summer & $R^{2}=0.8828$ \\
Autumn & $\nabla T=0.8761 \cdot T_{\text {top }}-28.4320$ \\
Winter & $R^{2}=0.9161$ \\
& $\nabla T=0.3261 \cdot T_{\text {top }}-4.2576$ \\
$R^{2}=0.9244$ \\
S
\end{tabular}


The load was simplified to that on a square area with a side length of $26.6 \mathrm{~cm}$ at the top of the panel and $25 \mathrm{~cm}$ from the corner edge of the panel under static loads. The thirdgrade loads were 50,70 , and $90 \mathrm{kN}$.

2.4.2. Boundary Conditions. In the initial analysis step, the panel boundary conditions were set as follows:

$$
\begin{aligned}
& \text { Slab - X: } U_{2}=U_{R_{2}}=U_{R_{3}}=0, \\
& \text { Slab-Y: } U_{1}=U_{R_{1}}=U_{R_{3}}=0,
\end{aligned}
$$

where $U_{1}$ and $U_{2}$ are the translational displacements in the directions of Models 1 and 2, respectively, and $U_{R_{1}}, U_{R_{2}}$, and $U_{R_{3}}$ are the rotation angles centered on axes 1,2 , and 3 , respectively.

In this model, the soil base was not set. Instead, an elastic modulus of $50 \mathrm{MPa}$ was directly set at the bottom of the subbase as the boundary condition.

2.5. Model Meshing. Nonuniform grid technology is applied in this model, considering that this paper is mainly to study the variation law of deflection at the center point of plate angle load under the coupled action of temperature and load. Therefore, the mesh division of cement concrete pavement slab is more intensive than that of the base layer. Considering the particularity of the loading area, the cement concrete pavement slab was split several times, and the three-dimensional finite element overall model of the cement concrete pavement and the partition effect of the pavement slab mesh were obtained as shown in Figure 2.

\section{Temperature Correction for Dynamic Deflection of Cement Pavement}

\subsection{Pavement Plate Angle Deflection under Coupled Effect of} Temperature and Load under Different Climatic Conditions. In Table 3, data for each season cement pavement, the measured top plate temperature, bottom plate temperature, and temperature difference indicated that the average temperature of the season's plate for the top and bottom temperature difference was significant. However, the difference between the average temperature of the plate bottom for each season was not significant. Hence, the coupled effects of the pavement void deflection in four seasons at the same temperature difference and load were analyzed.

The deformation of the plate angle load center point in the finite element model of cement concrete pavement under the temperature stress and the coupled temperature-load effect was determined. Equation (2) was then introduced to calculate the corresponding deflection of the plate angle load center point at various temperature differences:

$$
D_{1}=L_{1}-L_{2} \text {. }
$$

In equation (2), $D_{1}$ is the deflection value of the center point of the plate corner load, considering the effect of the temperature stress field $(\mu m) . L_{1}$ is the deformation of the

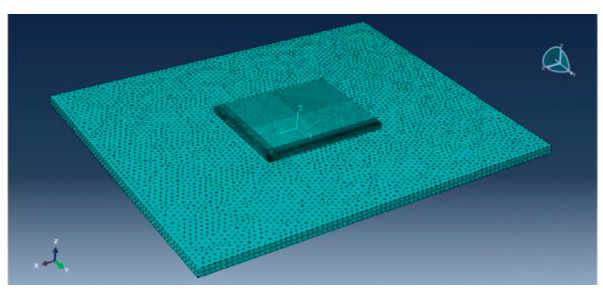

FIGURE 2: Overall meshing effect of three-dimensional finite element model for cement pavement.

center point of the plate corner load, considering the combined action of the temperature and load stress field $(\mu m) . L_{2}$ is the deflection value of the center point of the plate corner load, considering only the temperature stress $(\mu m)$.

Equation (2) was used to compute the load center point for each season and the values of the corresponding deflection at the temperature difference (Figure 3 ). The following observations were made.

(1) The deflection under the coupled action of the temperature stress and the tertiary load at the negative and positive temperature differences at the center point of the plate angle load in each season was significant.

(2) At the same temperature difference, there was no significant difference in deflection between the four seasons, and the deflection fluctuated slightly above and below the mean value in each season.

(3) At the same temperature difference, the deflection of the plate angle load center point increased with the load.

(4) Under the coupled action of temperature and load, the average error of the deflection value of the plate angle load center point in each season relative to the deflection value of the annual plate angle load center point is less than $3 \%$. Therefore, under the action of temperature and load coupling, the average deflection of the center point of angle load in four seasons is taken as the deflection of the center point of angle load in the whole year.

The variation trend of deflection at the center point of the plate angle load under the coupled action of temperature and three-stage loading was analyzed (Figure 4). The following was found:

(1) At the same temperature difference and under the same load, the effect of the void depth on the deflection could be ignored. The void depth increased with the void radius, and the deflection variation range between different void radii was broad.

(2) At the same temperature difference, the deflection under each void condition decreased with increasing temperature difference when the temperature difference was negative but increased with increasing temperature difference when the temperature difference was positive. 


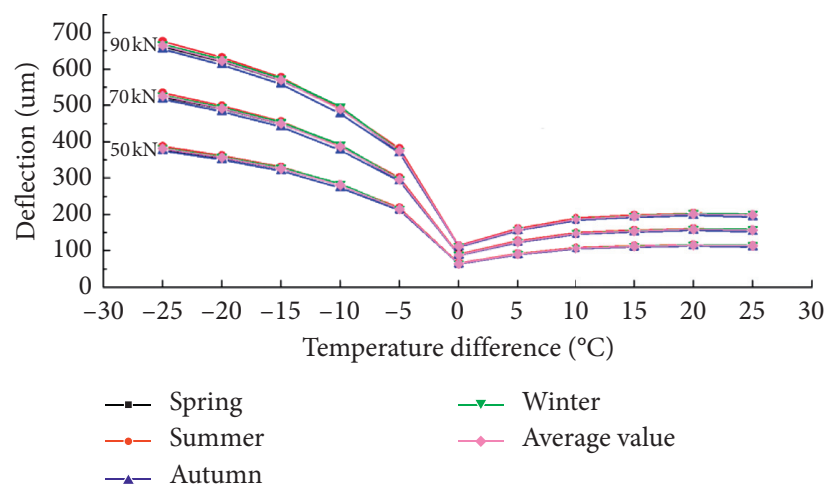

Figure 3: Deflection of plate angle load center point under coupled action of temperature and three-stage load for each season.
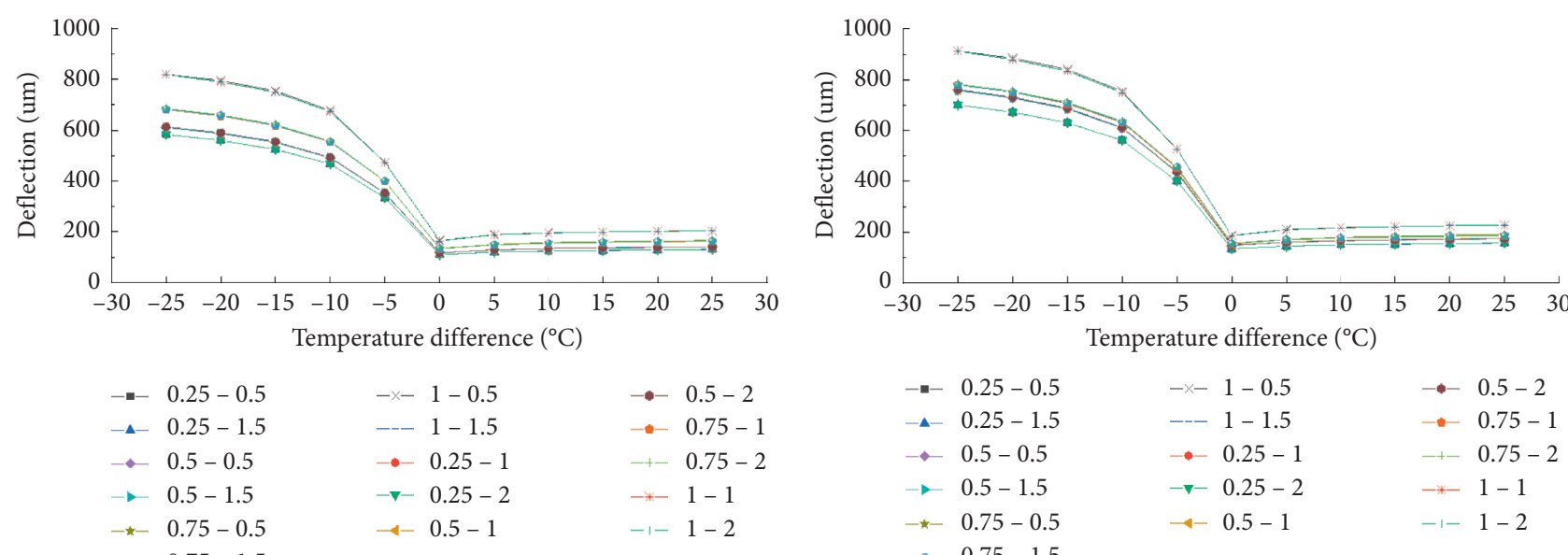

(a)

(b)

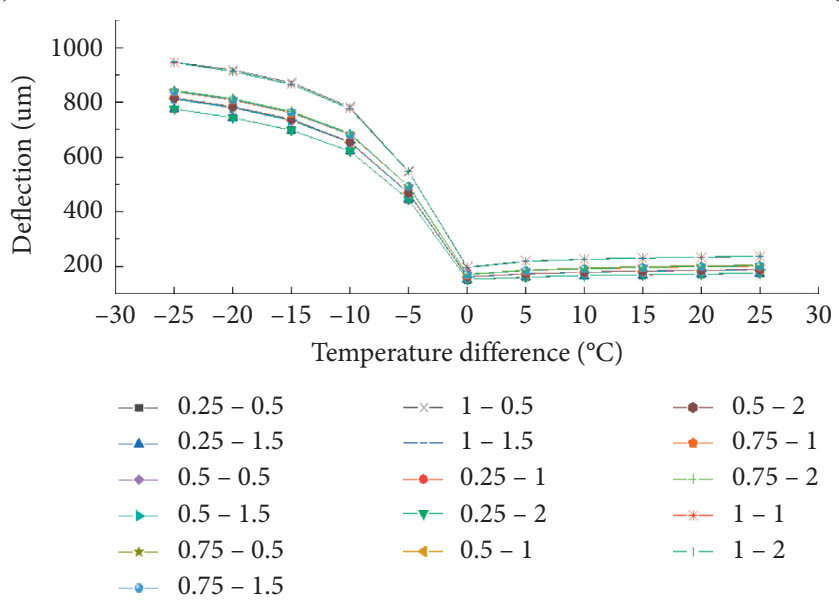

(c)

Figure 4: Deflection of plate angle load center point for plate angle voids. (a) $50 \mathrm{kN}$. (b) $70 \mathrm{kN}$. (c) $90 \mathrm{kN}$.

(3) Under the same void condition, the deflection increased with the load at the same temperature difference.

Figure 5 shows the variation of the deflection at the center point of the plate angle load for each plate edge void under the coupled action of temperature and three-stage load. The following observations were made:

(1) At the same temperature difference and under the same load, the deflection increased with the void depth but within a narrow range; the deflection 


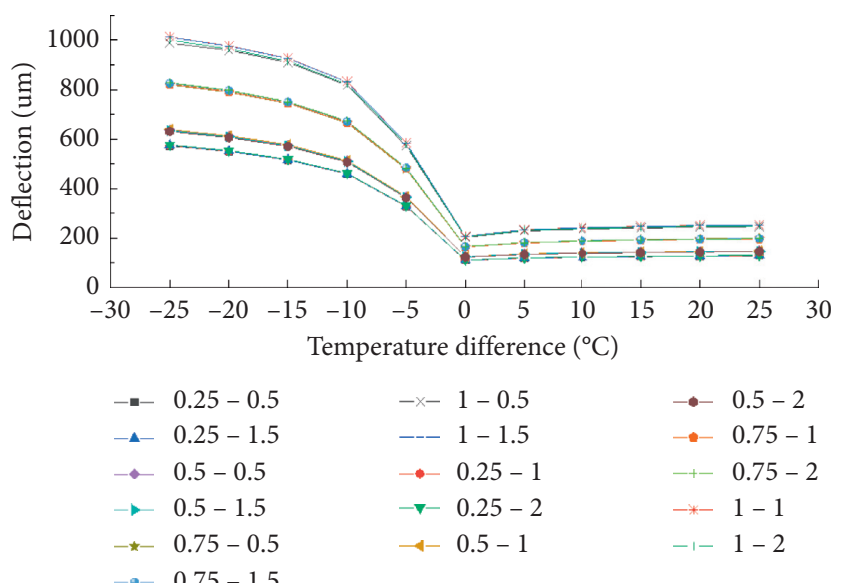

(a)

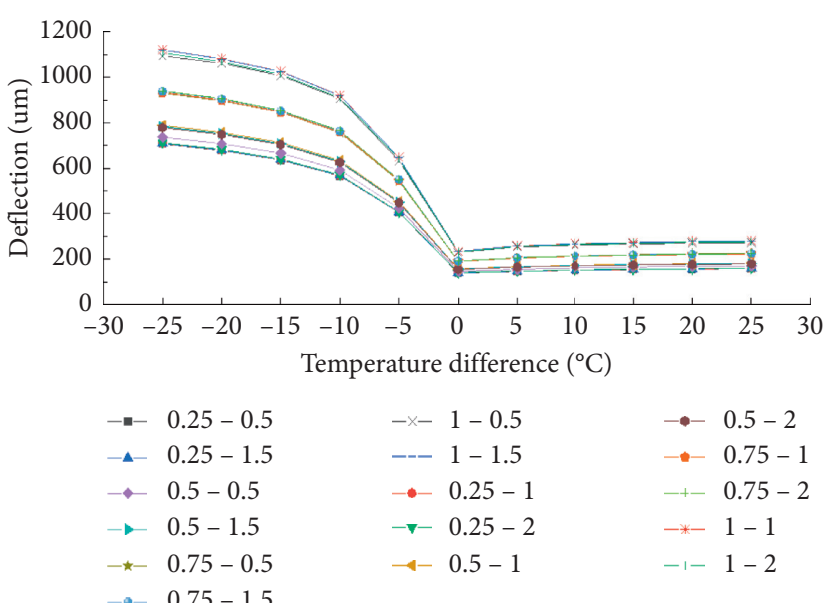

(b)

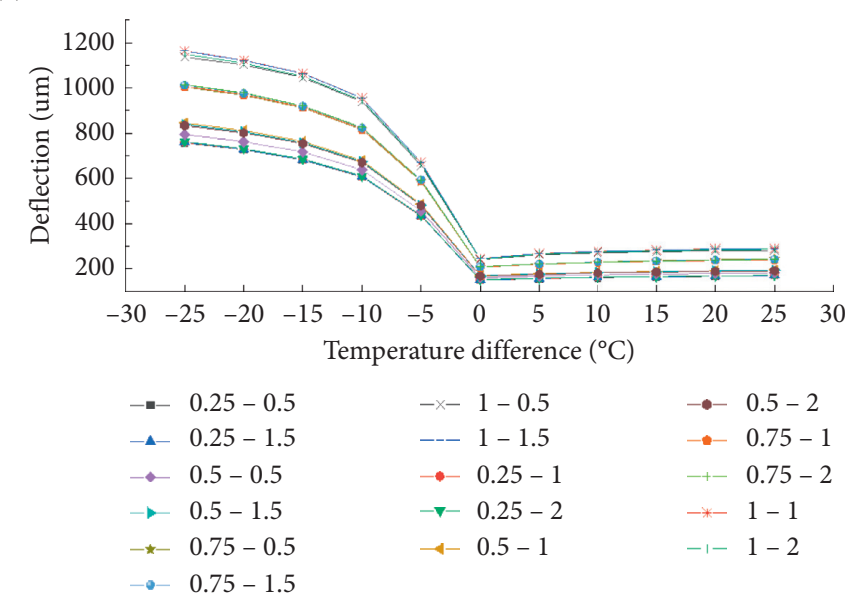

(c)

FIGURE 5: Deflection at plate angle load center point under plate edge void conditions. (a) $50 \mathrm{kN}$. (b) $70 \mathrm{kN}$. (c) $90 \mathrm{kN}$.

increased with the void width; and the deflections among the different void widths exhibited significant variations

(2) At the same temperature difference, the deflection under each void condition decreased with increasing temperature difference when the temperature difference was negative but increased with increasing temperature difference when the temperature difference was positive

(3) Under the same void condition, the deflection increased with the load at the same temperature difference

The comparison between Figures 4 and 5 shows that, at the same temperature difference and under the same load, the deflection under the plate edge void condition is larger than that under the plate angle void condition.

\subsection{Correlation Analysis between Pavement Temperature} Difference and Correction Coefficient. In this study, the modification coefficient of the influence degree of temperature difference on the deflection of the center point of the plate angle load was introduced and denoted as $\varphi$. The coefficient is calculated using

$$
\varphi=\frac{D_{1}}{D_{2}}
$$

where $\varphi$ is the correction coefficient of the temperature difference to the deflection value of the center point of the plate angle load and $D_{2}$ is the deflection value of the center point of the plate corner load, ignoring the effect of the temperature stress field $(\mu m)$.

The deflection values for the center point of the plate angle loads of 50,70, and $90 \mathrm{kN}$ (without considering the temperature effect) obtained through numerical simulation are listed in Table 5.

The correction coefficient distributions and the corresponding fitting curves for the deflections at the center point of the plate angle loads of 50,70 , and $90 \mathrm{kN}$ were calculated and plotted (Figure 6).

The following results were obtained.

(1) Within the negative temperature range, the correction coefficient decreased with an increase in the 
TABLe 5: Deflections at plate angle load center point under three-stage loads (without considering temperature effect).

\begin{tabular}{lccc}
\hline Load/kN & 50 & 70 & 90 \\
\hline Deflection at load center point $/ \mu m$ & 66.12 & 92.57 & 119.02
\end{tabular}

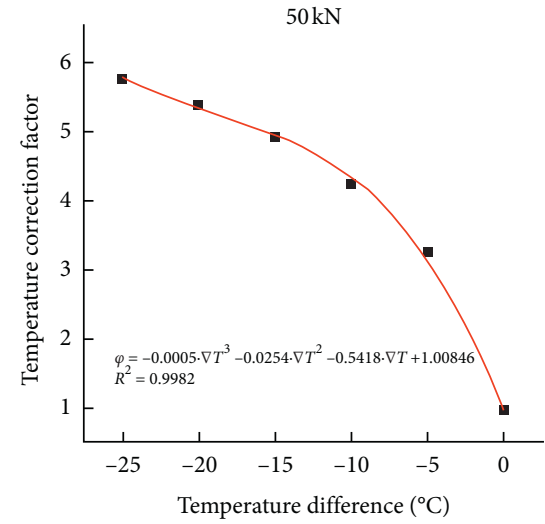

$50 \mathrm{kN}$

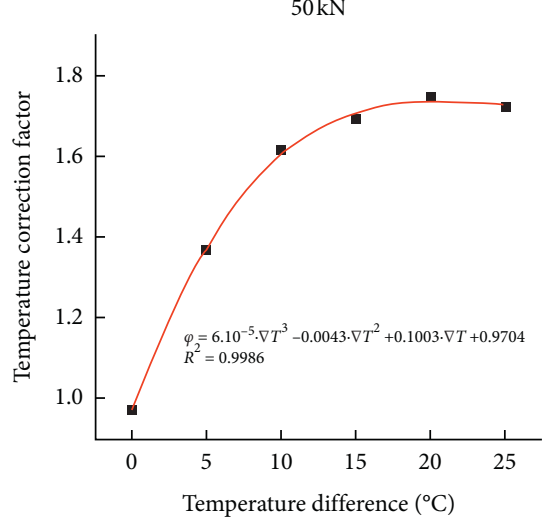

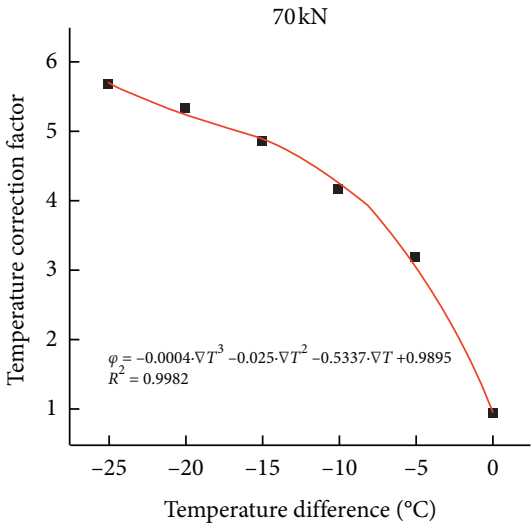

(a)

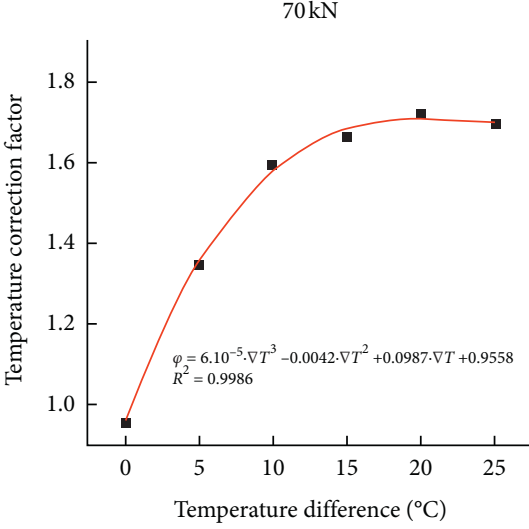

(b)

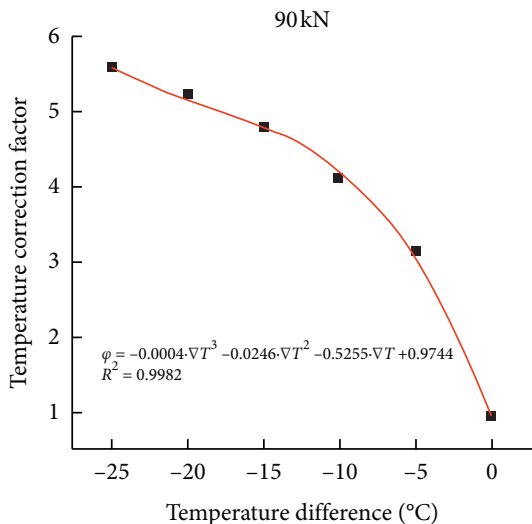

$90 \mathrm{kN}$

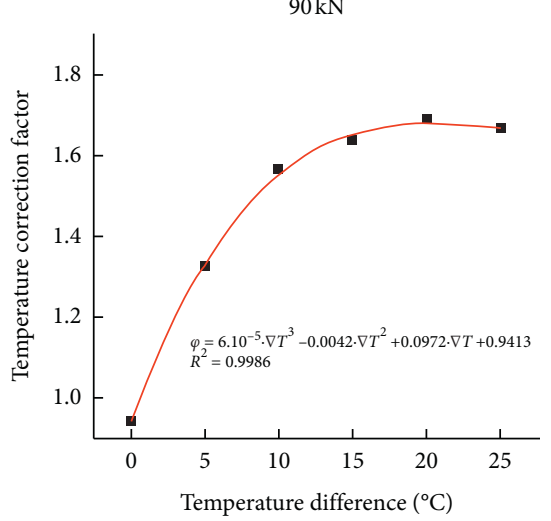

FIgURE 6: Correlation between temperature difference and correction coefficient under three loads. (a) Negative temperature range. (b) Positive temperature range.

temperature difference; in the positive temperature range, however, the correction coefficient increased with increasing temperature difference, and finally tended to be stable

(2) At the same temperature difference, the correction coefficient did not change significantly with an increase in the load

The relative error between the correction coefficients that corresponded to different temperature differences and their mean values under the three-stage load was not more than $5 \%$. Therefore, the average correction coefficient under the three-stage load represented the temperature correction coefficient under different loads, the calculated average temperature correction coefficient was sorted out, and the fitting curves were plotted, as shown in Figure 7.

When the positive and negative temperature differences were obtained, the correlation between the temperature difference and the correction coefficient could be expressed as follows.
Negative temperature range:

$$
\begin{aligned}
\varphi & =-0.0004 \cdot \nabla T^{3}-0.025 \cdot \nabla T^{2}-0.5337 \cdot \nabla T+0.9895, \\
R^{2} & =0.9982 .
\end{aligned}
$$

Positive temperature range:

$$
\begin{aligned}
\varphi & =6 \cdot 10^{-5} \cdot \nabla T^{3}-0.0042 \cdot \nabla T^{2}+0.0987 \cdot \nabla T+0.9558, \\
R^{2} & =0.9986 .
\end{aligned}
$$

Based on the plate angle deflection values of the cement concrete pavement plate that corresponds to the difference in temperature obtained during the temperature field variation tests, equations (4) and (5) were used to calculate the corresponding plate angle center deflections. The comparison is depicted in Figure 8. It was found that the actually detected deflection value fluctuates up and down the 


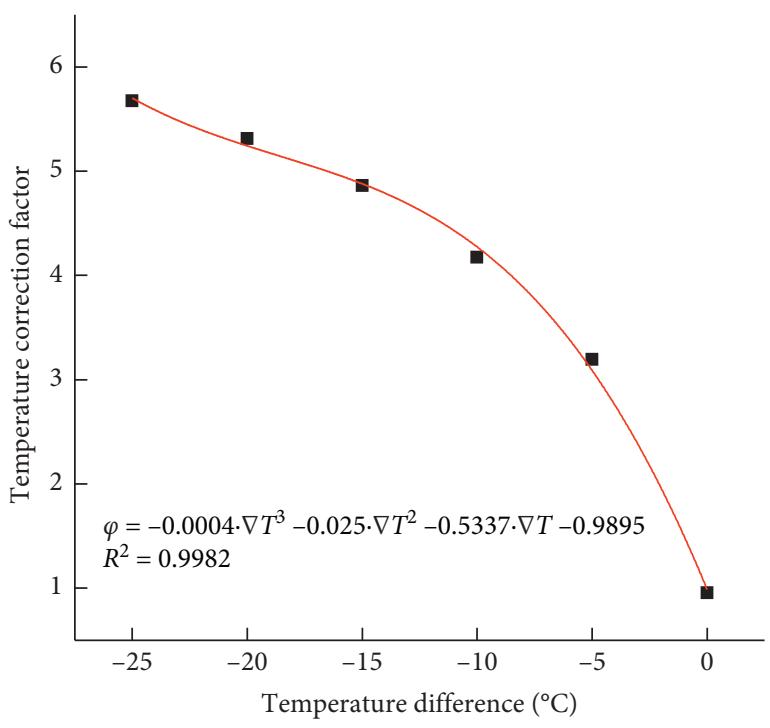

(a)

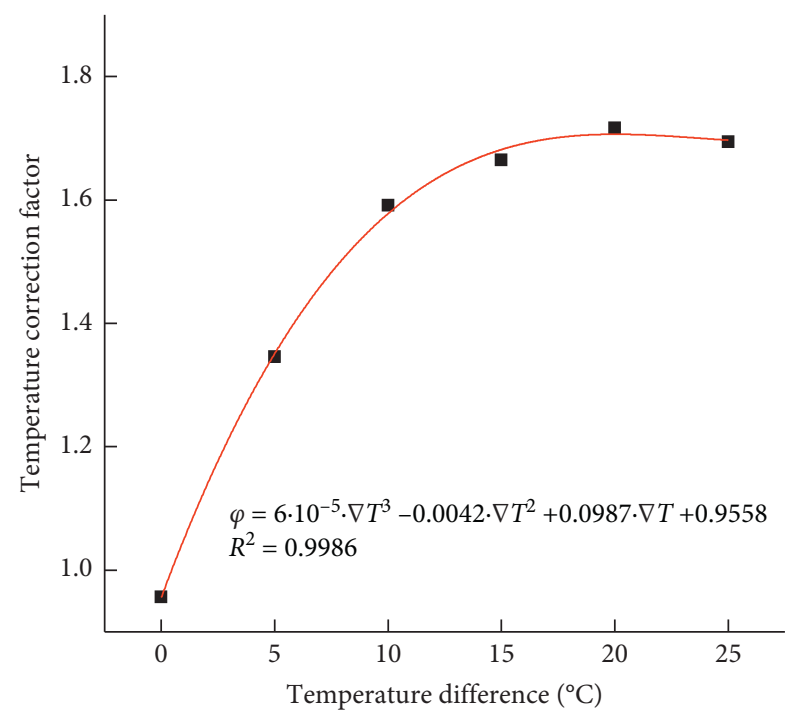

(b)

Figure 7: Correlation between positive and negative temperature differentials and mean correction coefficient. (a) Negative temperature range. (b) Positive temperature range.

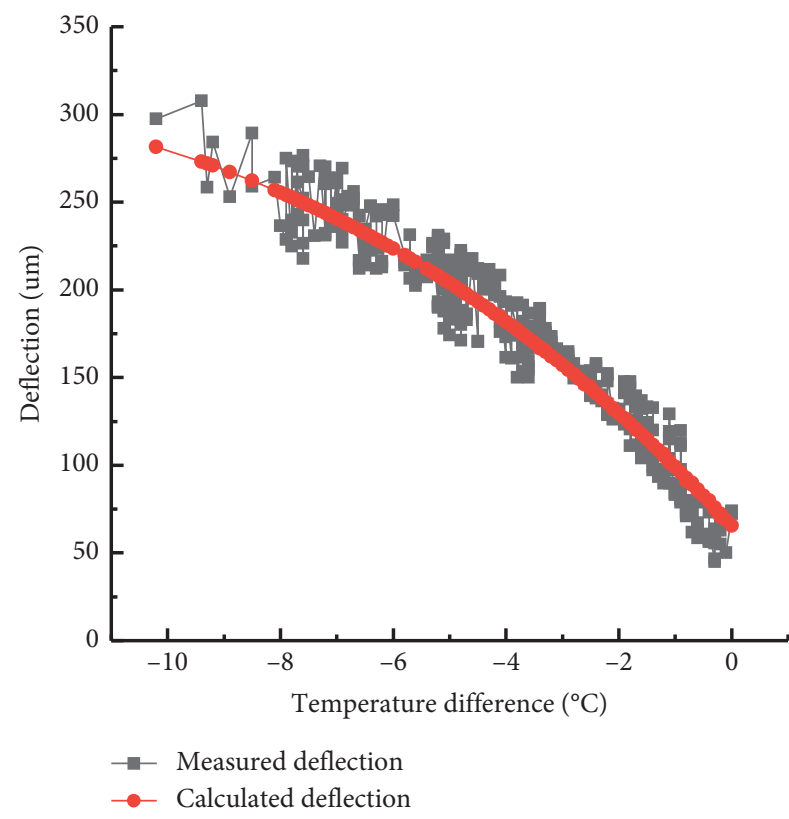

(a)

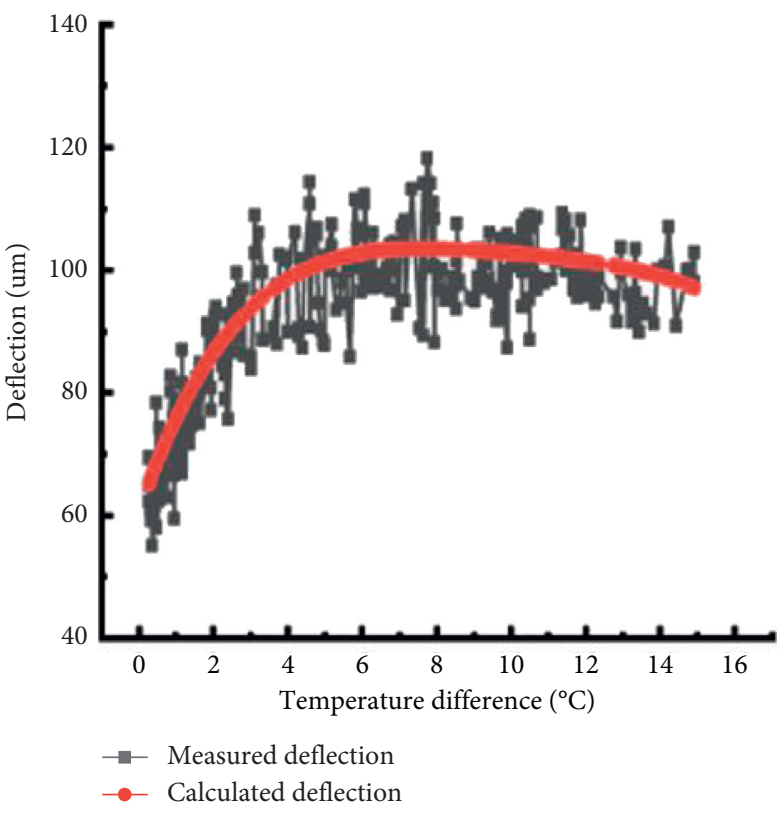

(b)

FIGURE 8: Comparison between experimental and the calculated deflection values of positive and negative temperature differences. (a) Negative temperature range. (b) Positive temperature range.

calculated value, the entire variation trend of the plate with the calculated data was fitted, and the finite element model was validated using equations (4) and (5). The accuracy of the simulated results was consistent with the test results.

The average temperature correction coefficients under different plate edge void conditions were analyzed (Figure 9).

The fitting analytical equations are expressed as follows.
Negative temperature range:

$$
\begin{aligned}
\varphi & =-0.0003 \cdot \nabla T^{3}-0.0218 \cdot \nabla T^{2}-0.4928 \cdot \nabla T+1.0010, \\
R^{2} & =0.9997 .
\end{aligned}
$$

Positive temperature range: 


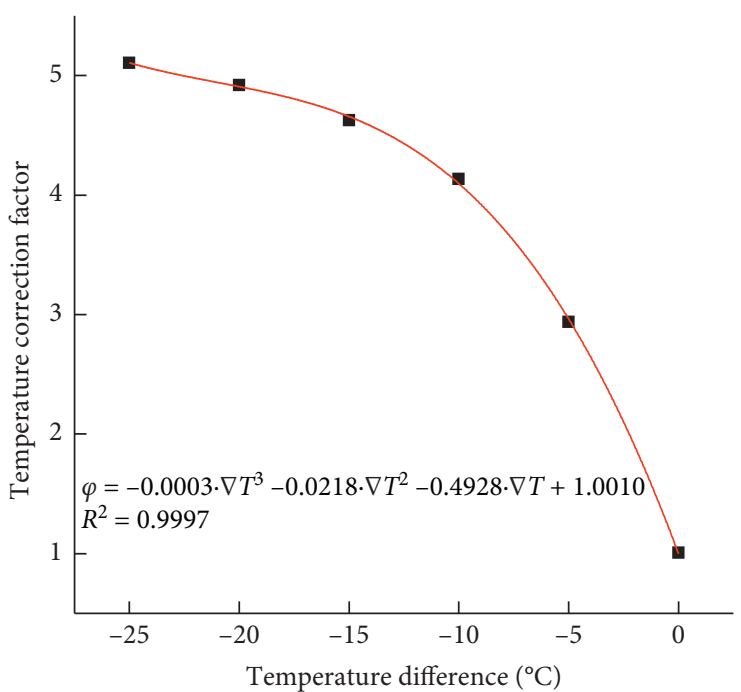

(a)

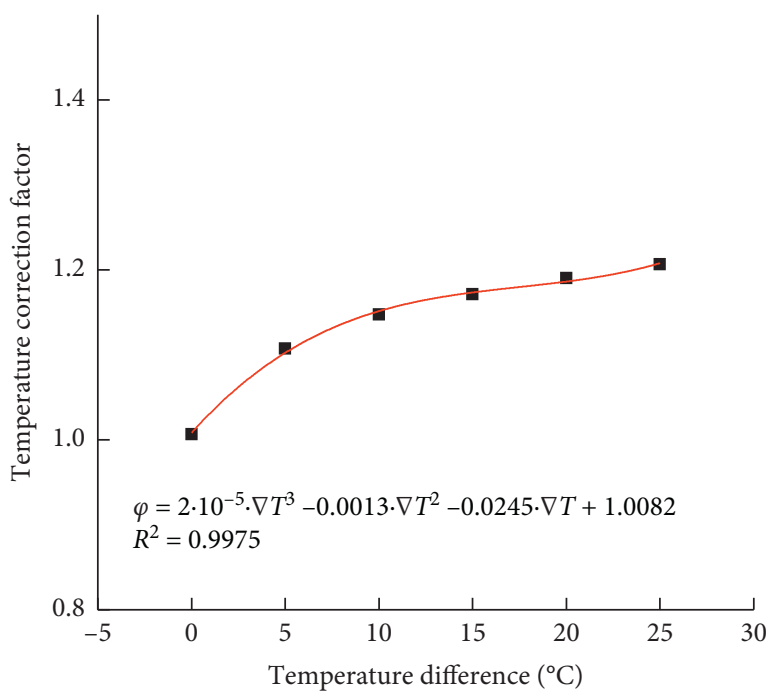

(b)

FIGURE 9: Correlation between positive and negative temperature differentials and correction coefficient. (a) Negative temperature range. (b) Positive temperature range.

$$
\begin{aligned}
\varphi & =2 \cdot 10^{-5} \cdot \nabla T^{3}-0.0013 \cdot \nabla T^{2}+0.0245 \cdot \nabla T+1.0082, \\
R^{2} & =0.9975
\end{aligned}
$$

Furthermore, the average temperature correction coefficients under different plate edge void conditions were evaluated (Figure 10).

The fitting analytical equations are expressed as follows.

Negative temperature range:

$$
\begin{aligned}
\varphi & =-0.0003 \cdot \nabla T^{3}-0.0214 \cdot \nabla T^{2}-0.4854 \cdot \nabla T+1.0006, \\
R^{2} & =0.9997 .
\end{aligned}
$$

Positive temperature range:

$$
\begin{aligned}
\varphi & =2 \cdot 10^{-5} \cdot \nabla T^{3}-0.0011 \cdot \nabla T^{2}+0.0218 \cdot \nabla T+1.0078, \\
R^{2} & =0.9984
\end{aligned}
$$

3.3. Temperature Correction Factor. The temperature difference-mean temperature correction coefficient relationship for the plate angle void (Figure 9) and plate edge void (Figure 10) conditions were compared and analyzed, as depicted in Figure 11.

The variation trends of the temperature differenceaverage temperature correction coefficients obtained analytically and through the calculation of the two types of cement concrete pavement void conditions were consistent (Figure 11), and the relative error was lower than $1 \%$. Therefore, considering the temperature difference-temperature correction factor obtained using equations (6) and (8), the mean value was adopted as the temperature correction factor under the void conditions at negative temperatures. Similarly, by considering the temperature difference-temperature correction factor obtained using equations (7) and (9), the mean value was selected as the temperature correction factor under the void condition at positive temperatures.

Negative temperature range:

$$
\begin{aligned}
\varphi & =-0.0003 \cdot \nabla T^{3}-0.0216 \cdot \nabla T^{2}-0.4888 \cdot \nabla T+1.0002, \\
R^{2} & =0.9997 .
\end{aligned}
$$

Positive temperature range:

$$
\begin{aligned}
\varphi & =2 \cdot 10^{-5} \cdot \nabla T^{3}-0.0011 \cdot \nabla T^{2}+0.0229 \cdot \nabla T+1.0092, \\
R^{2} & =0.9981 .
\end{aligned}
$$

\section{Field Test Verification}

4.1. Experimental Verification. Outdoor full-scale experimental tests can reflect the actual pavement conditions in a complex environment better. Hence, the test section of the comprehensive test site of the Water Conservancy and Traffic Infrastructure Safety Protection of Zhengzhou University was investigated to improve the consistency of test results. Design data for standard cement concrete pavements were adopted: the plane size was $4 \mathrm{~m} \times 5 \mathrm{~m}, 24 \mathrm{~cm}$ thick concrete pavement was placed on $18 \mathrm{~cm}$ thick cement stabilized macadam base, the subbase consisted of $16 \mathrm{~cm}$ thick graded broken stone, and six pavement plates were cast. A schematic of the pavement structure is depicted in Figures 12 and 13 .

Related instruments used for the validation test include a temperature sensor, hand-held infrared temperature 


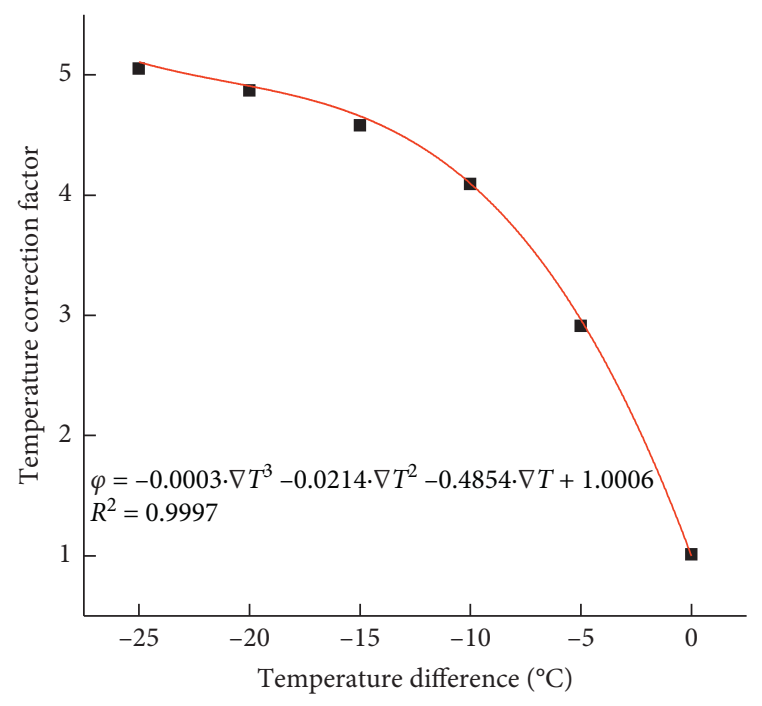

(a)

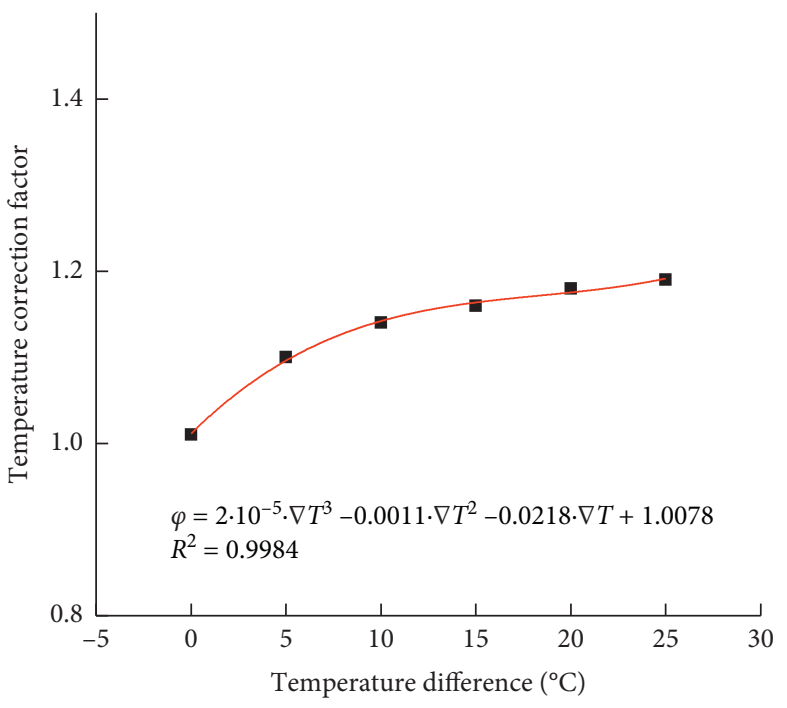

(b)

FIGURE 10: Correlation between positive and negative temperature differentials and correction coefficient. (a) Negative temperature range. (b) Positive temperature range.

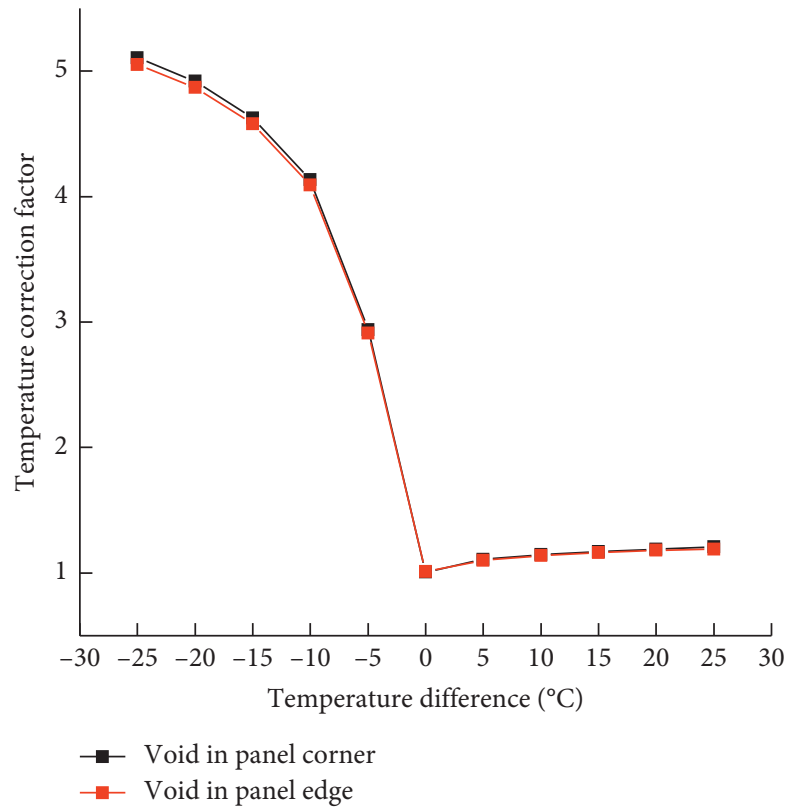

FIGURE 11: Temperature difference-mean temperature correction coefficient under plate angle void and plate edge void conditions.

detector, crane, FWD, hand-held grinding machine, and two cement concrete pavement plates with stable foundations. One plate was used to simulate the conditions of the plate corner voids, and the other plate was used to simulate the conditions of the plate edge voids. The field test process is shown in Figure 13, and the specific experimental steps were as follows:

(1) The temperature sensor was embedded in the specific location of the predrilled cement concrete pavement slab, and the buried depth was the thickness of the pavement slab. After the sensor was embedded, it was sealed with premixed cement concrete and compacted with force.

(2) The intact cement concrete pavement slab without voids was lifted using a crane, and the panel corner void was set at the corner of the top panel of the base course with the plate angle fixed as the circle center; the void radius and void depth were $1 \mathrm{~m}$ and $2 \mathrm{~cm}$, respectively. The panel edge void was set at the edge of the top slab of the base course with $0.5 \mathrm{~m}$ as the void width and $2 \mathrm{~cm}$ as the void depth. 

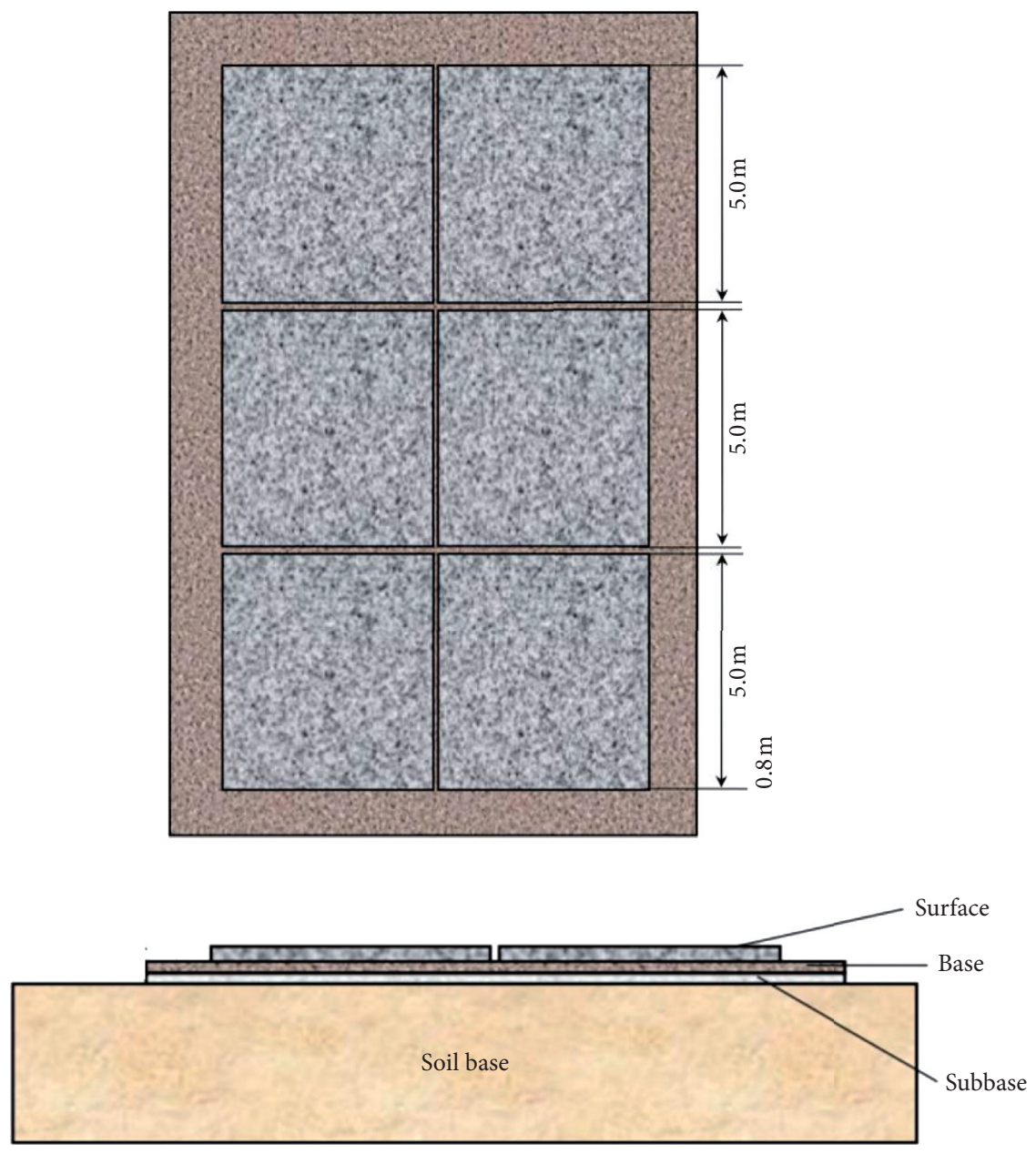

FiguRE 12: Schematic of full-scale cement concrete pavement structure.
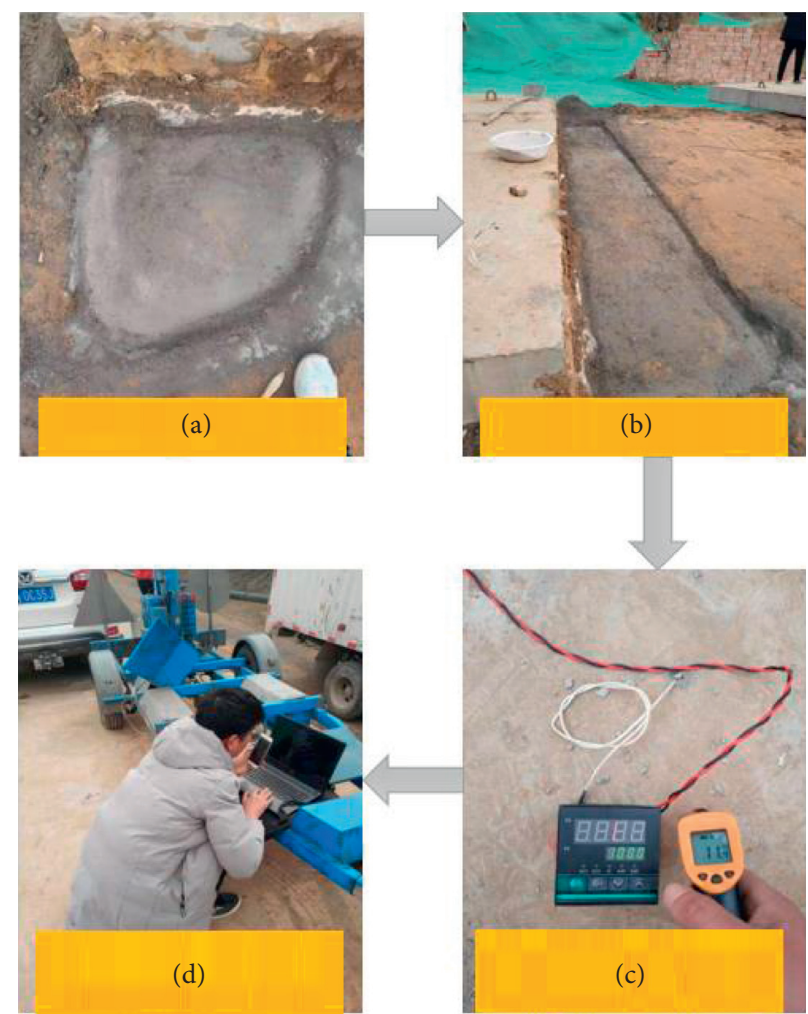

FiguRE 13: Flow chart of the field test. (a) Void in panel corner. (b) Void in panel edge. (c) Road surface temperature detection. (d) Detection of road surface deflection. 


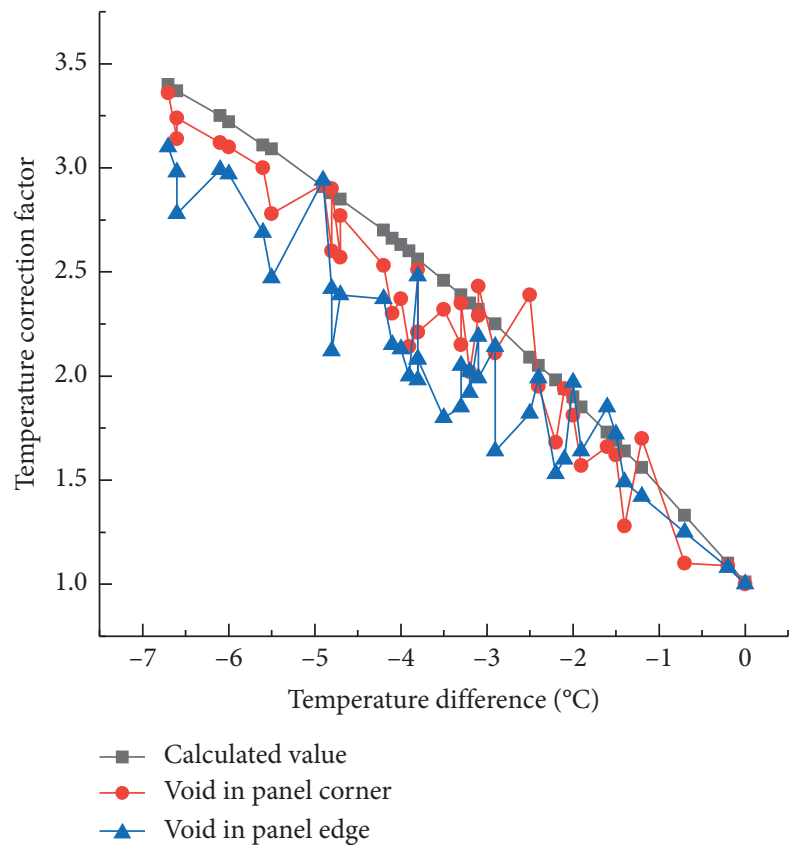

(a)

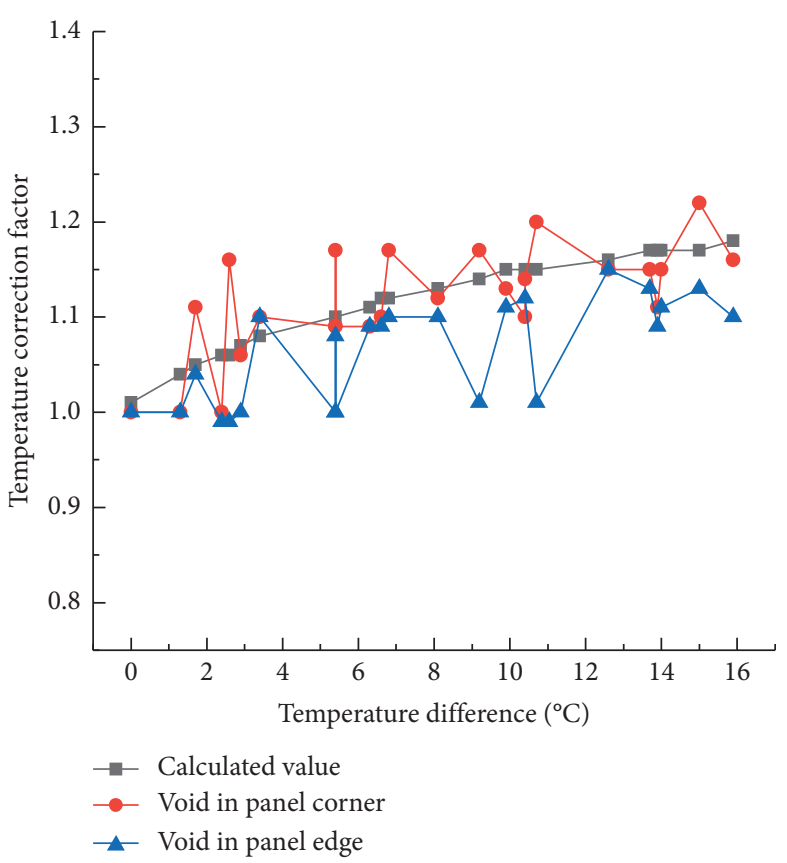

(b)

FIGURe 14: Comparative analysis of model calculated values and field test results. (a) Negative temperature range. (b) Positive temperature range.

(3) In addition, an infrared temperature detector was used to collect temperature data for the top and bottom of the slab, and an FWD was used to collect deflection data for the center point of the plate corner load. The interval for the above data collection was once every $1 \mathrm{~h}$.

4.2. Analysis of Test Results. After the above test data were sorted, the deflection value corresponding to a zero temperature difference during daily tests was selected as the standard value of all the deflection tests for that day, and the ratios of all deflection values (including zero temperature difference) to the above standard value was counted, in other words, the temperature correction coefficient (Figure 14).

A comparison between the model results and test results showed that when the pavement slab had a negative temperature difference, the actual temperature correction coefficient of the panel corner and edge voids fluctuated up and down within a narrow fluctuation range, and the average fluctuation was not higher than $7 \%$. When the pavement slab had a positive temperature difference, the actual temperature correction coefficients of the panel corner and edge void fluctuated within a narrow fluctuation range of less than $5 \%$ on the average. These results show that, in practice, the temperature correction coefficient can be used for correcting the measured deflection precisely.

\section{Conclusion}

In this study, through the establishment of coupled temperature and load finite element model of cement pavement, the effect of temperature difference at the bottom and top of the slab and deflection of the center point of the plate corner load under different void, climatic, and load conditions was investigated. In addition, the temperature difference between the top and bottom and the correlation of deflection temperature correction coefficient was analyzed. Furthermore, the temperature correction coefficient was developed considering the temperature difference between the top and bottom, and the accuracy of the temperature correction coefficient was verified experimentally.

(1) Based on the monitoring and analysis of the temperature field of a cement concrete pavement through full-size outdoor tests for up to one year, the relationship between the plate top temperature of the cement concrete pavement and the temperature difference at plate top and bottom of the cement concrete pavement in each season was established.

(2) The deflection of the plate angle load center point under the coupled action of temperature and load in each season was calculated, and its variation was evaluated. It was found that, considering the effect of the temperature difference, the deflection decreased with increasing negative temperature difference but decreased with increasing positive temperature difference under each void condition.

(3) At the same temperature difference, the deflection difference of the center point of the plate angle load under different void conditions was small.

(4) The temperature correction coefficient was introduced to derive the deflection correction equation for the cement pavement, considering the temperature difference in different seasons and under 
different void conditions. In the case of a negative temperature difference, the correction coefficient decreased with an increase in temperature difference; at a positive temperature difference, the correction coefficient increased with an increase in temperature difference.

(5) Two specific conditions of plate corner and plate edge voids were selected for the tests. It was found that the error between the measured and calculated values of the temperature correction coefficients for these two conditions was not higher than $7 \%$, which demonstrated the accuracy of the temperature correction coefficient.

\section{Data Availability}

The data used to support the findings of this study are included within the article.

\section{Conflicts of Interest}

The authors declare that they have no conflicts of interest.

\section{Acknowledgments}

The authors acknowledge the support received from the National Key Research and Development Plan (Grant no. 2018YFB1600200), the National Natural Science Foundation of China (Grant nos. 51878624 and 51878622), Major Scientific and Technological Special Project in Henan (Grant no. 181100310400), Henan Science Fund for Distinguished Young Scholars (Grant no. 202300410354), Natural Science Foundation of Henan Province (Grant no. 202300410746), the Program for Science and Technology Innovation Talents in Universities of Henan Province (Grant no. 19HASTIT041), and Key Research Projects of Higher Education in Henan Province (Grant no. 18A580001).

\section{References}

[1] Q. Chen, G. Wang, and W. Pan, "Research on relationships among different disease types of cement concrete pavement based on structural equation model," Mathematical Problems in Engineering, vol. 2020, no. 123X, 13 pages, Article ID 9580616, 2020.

[2] Z. Liu, F. Xu, and G. Cao, "Study on cement concrete pavement treatment methods of common damage diseases," Applied Mechanics and Materials, vol. 716-717, pp. 307-309, 2015.

[3] C. Zhang and Y. Cai, "Study on technologies of detecting voids in cement concrete pavement based on dynamic deflection," Master thesis, Zhengzhou University, Zhengzhou, China, 2016.

[4] L. I. Xiang and Y. Peng, "Dynamic response analysis of void under slab to cement concrete pavement," Journal of Beijing University of Technology, vol. 43, no. 12, pp. 1922-1928, 2017.

[5] Q. Wang, X. Wang, and C. Wang, "Differentiation of the cavity beneath cement pavement slab based on deflection difference and pumping height," Journal of Highway and Transportation Research and Development, vol. 25, no. 12, pp. 84-87, 2008.
[6] S. Chun Li, "Correlation of non-destructive pavement test devices," Advanced Materials Research, vol. 912-914, pp. 613-616, 2014.

[7] D. J. White, P. K. R. Vennapusa, and Y. Zhang, "Assessment of support conditions of concrete pavement using FWD deflection basin data," Journal of Testing and Evaluation, vol. 47, no. 4, pp. 21-29, 2018.

[8] Y. Huang, J. Yuan, Y. Tan et al., "Identification of void beneath airport cement concrete pavement and its influence," Journal of Tongji University: Natural Science, vol. 40, no. 6, pp. 861866, 2012.

[9] Y. H. Zhong, B. Zhang, C. C. Guo, and J. Qi, "Research on the identification method for void location of semi-rigid base pavement," Advances in Structural Engineering, vol. 94-96, pp. 1257-1260, 2011.

[10] C. Zhang, H. He, Y. Xue, and Z. Luo, "Comparative test and analysis of falling-ball instrument and FWD deflection detection method," in Proceedings of the IOP Conference Series: Earth and Environmental Science, vol. 514, p. 22065, Vienna, Austria, May 2020.

[11] R. Wu, Q. Peng, and J. Xiaobo, "Identification of the void between the cement concrete pavement slab and foundation based on finite element analysis using orthogonal experiment method," Gongcheng Lixue/Engineering Mechanics, vol. 25, no. Suppl P189, pp. 197-192, 2008.

[12] Y. Wu, T. Liu, Z. Huang, B. Chen, and Z. Zheng, "Experimental study on detection of void in concrete pavement slab by FWD," in Proceedings of the IOP Conference Series: Earth and Environmental Science, pp. 1755-1315, Vienna, Austria, May 2020.

[13] Z. H. A. O. Hongduo and M. A. Lukuan, "Investigation into effects of temperature variations on airport cement pavements based on measured data," Journal of Tongji University: Natural Science, vol. 47, no. 12, pp. 1764-1771, 2019.

[14] L. Wang and C. Hu, "Built-in temperature's regional characteristics of cement concrete pavement and its effect on slab curling," Journal of Traffic and Transportation Engineering, vol. 18, no. 3, pp. 19-33, 2018.

[15] L. Zhang, Y. Luo, X. Chen et al., "Temperature field characters and numerical simulation of asphalt overlay structure upon previous cement pavement surface," Journal of Highway and Transportation Research and Development, vol. 36, no. 5, pp. 11-19, 2019.

[16] L. Wen and X. Guo, Baozhu, "Cause analysis on the void under slabs of cement concrete pavement," in Proceedings of the IOP Conference Series: Materials Science and Engineering, vol. 205, Shenyang, China, 2017.

[17] S. Zeng, X. Zeng, and Xu Jia, "Criterion for void identification beneath cement concrete pavement slab corner," Journal of Central South University (Science and Technology), vol. 40, no. 1, pp. P248-P255, 2009.

[18] S. Chen, Z. Wang, C. Zhang et al., "Dynamic finite element simulation analysis of void in cement concrete pavement," Journal of China \& Foreign Highway, vol. 37, no. 4, pp. 53-57, 2017.

[19] C. Toth, C. Toth, Szentpeteri, and I. Szentpeteri, "Effects of climatic factors on the shape of deflection bowl," in Proceedings of the 3rd International Conference on Road and Rail Infrastructure-CETRA 2014: Road and Rail Infrastructure III, University of Zagreb, Split, Croatia, April 2014.

[20] T. Jing and Z. Yan, "Research on the temperature status of cement concrete pavement," Journal of Tongji University, vol. 5, no. 3, pp. 88-98, 1980. 
[21] X. Duan, The Thermal Stress Study of Void beneath Slab on Cement Concrete Pavement, Chongqing Jiaotong University, Chongqing, China, 2016.

[22] J. Zhao, Z. Tan, and B. Liu, "Effect and correction on slab interior deflection of cement concrete pavement due to temperature gradient," Journal of Tongji University (Natural Science), vol. 35, no. 5, pp. 617-620, 2007.

[23] L. I. Sheng, S. Chen, Z. Liu, and H. Zhan, "Some problems on deflection test of old cement concrete pavement," Journal of Central South University (Science and Technology), vol. 46, no. 12, pp. 4713-4718, 2015.

[24] Y. Dou, M. Song, J. Sun, F. Xiong, and S. Zheng, "Numerical analysis of cement concrete pavement crack under the coupling of temperature and load," Concrete, vol. 40, no. 6, pp. 56-60, 2018.

[25] S. Li, B. Zhang, F. Wang et al., "Experimental study on correction of deflection temperature of cement concrete pavement," Master Thesis, Zhengzhou University, Zhengzhou, China, 2019.

[26] Y. Ding and Y. Zhong, "Identification of void in cement concrete pavement and evaluation of polymer grouting effect by considering temperature's effection," Master thesis, Zhengzhou University, Zhengzhou, China, 2019. 